\title{
H1N1 Brand Power: Marketing a Disaster
}

\section{By Janis Huntington \& Amanda Jones}

In 2009, the emergence of the H1N1 virus captured the attention of everyone from the general public to multi-lateral organizations. Around the globe, governments and organizations diverted resources to implement influenza preparedness plans in response to this international "disaster". As new infectious diseases emerge and existing ones continue to spread, how is it possible that countries chose to spend billions of dollars on this particular disease? We don't need to look very far for the answer. In fact, no further than our favorite coffee shops or the markings on our shoes. It's all in the brand.

What is a brand? Simply put, a brand is "a collection of emotional and functional attributes [of a product] that strongly influences purchase". ${ }^{1}$ In the case of $\mathrm{H} 1 \mathrm{~N} 1$, the brand is that $\mathrm{H} 1 \mathrm{~N} 1$, with its potential for causing widespread disease, is an international health disaster that could recreate the devastation caused by the 1918 Spanish flu (estimated 20-40 million deaths) or the 1968 Hong Kong flu (1-4 million deaths). ${ }^{2}$ The devastation of past pandemics is hard to ignore. The frequent comparisons between these historic pandemics and H1N1 left the impression that anything less than a complete response would be negligent and a threat to the world's health, thus contributing to H1N1's brand value. ${ }^{3}$ What resulted from this line of thinking was the "purchase" of strategic planning for pandemic preparedness and the funneling of health care resources to prevent H1N1.

In order for a brand to be successful, it needs to be consistently used over time. Evidence of the H1N1 brand's consistency can be seen in how it was labeled "pandemic" in the WHO Pandemic Influenza classification system even before a single person was infected. By the time the public heard the announcement of the "potential" pandemic, it was already classified as Stage 4 (which signifies confirmed human to human transmission of a virus with no consideration to the number of individuals

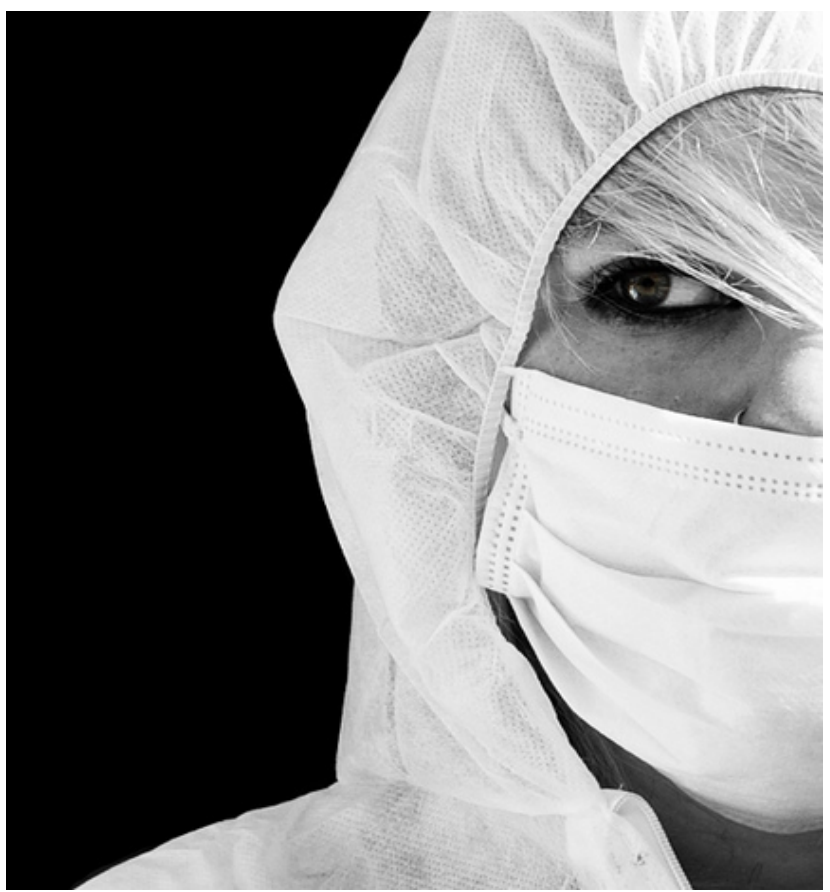

or regions affected). ${ }^{4}$ While influenza experts are aware that Phase 1 of a pandemic indicates that the recombinant virus is circulating only in animals, ${ }^{5}$ this distinction was rarely clarified in mainstream media. News items on the emerging H1N1 outbreak frequently mentioned past pandemics with devastating death tolls, building the public's association of H1N1 "pandemic" with immense loss of life. ${ }^{6}$ While the term "pandemic" is intended to refer to all diseases that are geographically widespread, it has become restricted primarily to influenza. When looking up "pandemic" with the definition feature of Google, seven out of ten related phrases directly refer to flu. . The H1N1 "pandemic" brand is also consistent in the scientific literature. For example, in 2009, there were 1,637 articles indexed on Medline with the keyword "H1N1"; $34 \%$ of those also used "pandemic." This is a striking percentage when compared to publications on other pandemic diseases such as HIV and tuberculosis. Of 
the articles published in 2009 that had the keywords "HIV" or "AIDS," (12,044) or "tuberculosis" $(4,282)$, only $0.88 \%$ of HIV/AIDS articles and only $0.70 \%$ of $\mathrm{TB}$ articles also contained the term "pandemic".

Why is it that influenza dominates the "pandemic" brand? The answer can be found in another well-established marketing strategy: know your target audience. The idea of a "pandemic" had to be appealing to the western culture before it could be globally marketable. Once international agencies decided influenza was a threat that demanded special attention, wealthy nations immediately launched into creating and implementing influenza preparedness strategies. However, before these countries could access the necessary resources, they needed to justify the spending to their constituents. If constituents were going to support influenza preparedness, they needed to feel at risk. For a disease, the brand is only as good as its potential impact - the number of people that it could infect and everyone is considered at risk for H1N1.

For a brand to have staying power it needs to deliver on its promise, and the H1N1 brand had promised a substantial health impact. In January 2010 the WHO issued an online press release in response to mass criticisms regarding how $\mathrm{H} 1 \mathrm{~N} 1$ had been defined by the WHO as a pandemic. The WHO stated that the evidence supporting these allegations was "scientifically wrong and historically inaccurate."7 The document was worded defensively, and upheld the promise that was built into the pandemic brand. ${ }^{7}$ The aim was to convince the H1N1 brand buyers that they had received their money's worth because that based on the WHO's definition of a pandemic, H1N1 certainly was one. While defending their position, they neglected to realize what the criticisms actually signified: despite the WHO's technical definitions, the world had been expecting a particular type of pandemic due to how H1N1 was branded and that pandemic was not delivered. Many critics are speculating about financial interests motivating recommendations regarding the purchase of H1N1 "products" (such as vaccines) ${ }^{8}$ but the point here is this: regardless of intent, H1N1 was marketed as a brand and that brand has failed. Unless the brand image is altered to reflect the product, the next time the world is faced with a new strain of influenza, the public may not be buying "pandemic" again. ${ }^{9}$

\section{Acknowledgements}

We would like to acknowledge Dr. Stephanie Yanow (Public Health Sciences, University of Alberta) and Gyde Shepherd (Communications Officer, Global Health Research Initiative) for their assistance in editing this paper.

\section{References}

1. Adams C, Lombardi N. Brand Impact: Defining a brand in today's economy. Royalties 2009; 4(5): 20-25.

2. World Health Organization. Pandemic Influenzae

Preparedness (Hue Regional Emergency Operations Training).

http://www.wpro.who.int/internet/files/eha/dir/Regiona $1 \% 20$ Training\%20Course\%20on\%20Emergency\%20Respons e\%20Operations/Day\%202\%20\%20Pandemic\%20Influenza \%20Preparedness.pdf (Accessed April 26, 2010).

3. Doshi P. Calibrated response to emerging infections. BMJ 2009 Sep 3; 339: b3471.

4. World Health Organization. Chronology of Influenza A (H1N1).

http://www.searo.who.int/EN/Section10/Section2562_14942. htm (Accessed April 26, 2010).

5. World Health Organization. Pandemic influenza preparedness and response.

http://www.who.int/csr/disease/influenza/pipguidance2009/en /index.html (Accessed April 26, 2010).

6. Cohen E. When a pandemic isn't a pandemic. http://edition.cnn.com/2009/HEALTH/05/04/swine.flu.pande mic/index.html (Accessed April 26, 2010).

7. Fukuda K. WHO Virtual press conference. January 14, 2010.

8. Zarocostas J. Head of the WHO's vaccines advisory group defends its policy on competing interests. BMJ 2010 Feb 17: 340: c987.

9. Watson R. WHO is accused of "crying wolf" over swine flu pandemic. BMJ 2010 Apr 6; 340: c1904.

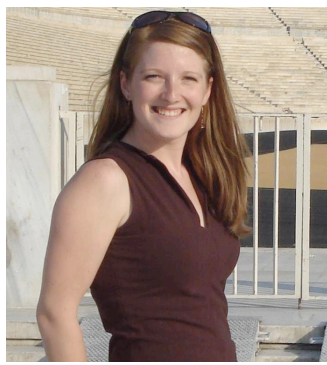

\section{Author Profiles}

Janis Huntington recently received a MSc degree in global health at the School of Public Health at the University of Alberta. Her main interests include infectious diseases, global health, community-driven research, and communication.

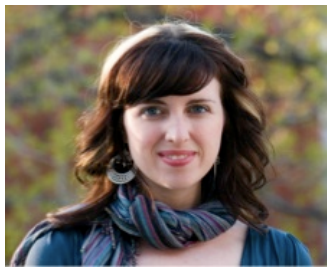

Amanda Jones is currently pusuing a MSc degree in global health at the School of Public Health at the University of Alberta. Her main interests include global health, infectious diseases, adolescent reproductive health, peer education, and participatory research methods. 